\title{
REL2, A Gene Encoding An Unknown Function Protein which Contains DUF630 and DUF632 Domains Controls Leaf Rolling in Rice
}

Shuai-Qi Yang ${ }^{1 \dagger}$, Wen-Qiang Li ${ }^{1 \dagger}$, Hai Miao ${ }^{1}$, Peng-Fei Gan', Lei Qiao ${ }^{1}$, Yan-Li Chang ${ }^{1}$, Chun-Hai Shi ${ }^{2 *}$ and Kun-Ming Chen ${ }^{1 *}$

\begin{abstract}
Background: Rice leaves are important energy source for the whole plant. An optimal structure will be beneficial for rice leaves to capture light energy and exchange gas, thus increasing the yield of rice. Moderate leaf rolling and relatively erect plant architecture may contribute to high yield of rice, but the relevant molecular mechanism remains unclear.

Results: In this study, we identified and characterized a rolling and erect leaf mutant in rice and named it as rel2. Histological analysis showed that the rel2 mutant has increased number of bulliform cells and reduced size of middle bulliform cells. We firstly mapped REL2 to a 35-kb physical region of chromosome 10 by map-based cloning strategy. Further analysis revealed that REL2 encodes a protein containing DUF630 and DUF632 domains. In rel2 mutant, the mutation of two nucleotide substitutions in DUF630 domain led to the loss-of-function of REL2 locus and the function of REL2 could be confirmed by complementary expression of REL2 in rel2 mutant. Further studies showed that REL2 protein is mainly distributed along the plasma membrane of cells and the REL2 gene is relatively higher expressed in younger leaves of rice. The results from quantitative RT-PCR analysis indicated that REL2 functioning in the leaf shape formation might have functional linkage with many genes associated with the bulliform cells development, auxin synthesis and transport, etc.
\end{abstract}

Conclusions: REL2 is the DUF domains contained protein which involves in the control of leaf rolling in rice. It is the plasma membrane localization and its functions in the control of leaf morphology might involve in multiple biological processes such as bulliform cell development and auxin synthesis and transport.

Keywords: Rice (Oryza sativa L.), Rolling and erect leaves, REL2, DUF domains, Bulliform cells

\section{Background}

Plant leaves are lateral organs and derived from the peripheral zone of the shoot apical meristem (SAM) (Sussex 1995; Bowman et al. 2002). As the leaf grows away from the meristem, its shape is decided by growing in three different axes, which are proximal-distal, abaxial-adaxial

\footnotetext{
*Correspondence: chhshi@zju.edu.cn; kunmingchen@nwsuaf.edu.cn; kunmingchen@163.com

${ }^{\dagger}$ Equal contributors

2Department of Agronomy, College of Agriculture and Biotechnology, Zhejiang University, Hangzhou 310058, Zhejiang, People's Republic of China ${ }^{1}$ State Key Laboratory of Crop Stress Biology in Arid Areas, College of Life Sciences, Northwest A\&F University, Yangling 712100, Shaanxi, People's Republic of China
}

and medial-lateral. Among these three axes, the adaxialabaxial axis is the foundation of the subsequent asymmetric growth of the leaf and lamina expansion (Waites and Hudson 1995; McConnell and Barton 1998; Moon and Hake 2011). Rice is one of the most important crops in the world and how to increase grain yield has become a focus on rice research. Appropriate leaf shape is an important characteristic to construct the super-high-yield hybrid rice, which means long, narrow, V-shaped (rolling) and thick leaves of the top three leaves (Yuan 1997). Moderate leaf rolling will be beneficial to the erectness of leaves, thus minimizing shadowing among leaves, which contributes to improving 
photosynthetic efficiency and grain yield (Zhang et al. 2009; Xiang et al. 2012). In order to achieve a breakthrough of rice yield, isolation and identification of rolling leaf genes is a necessary way to construct ideal plant architecture with moderate leaf rolling (Price et al. 1997).

The genetic mechanism behind leaf in adaxial-abaxial axis development is relatively clear in Arabidopsis thaliana. Many mutants have been investigated and the results illustrated that HOMEODOMAIN-LEUCINE ZIPPERIII (HD-ZIPIII), KANADI and the small RNA pathway play significant roles to determine the shape in adaxial-abaxial growth (for a review Moon and Hake 2011). However, the mechanism about leaf in adaxialabaxial axis development in rice is still in exploration and not so clear. Generally, there are two types of leaf rolling in rice, adaxial rolling and abaxial rolling. To date, more than fourteen rolling leaf $(r l)$ mutants in rice were isolated and mapped genetically. Among these mutants, six recessive genes $(r l 1-r l 6)$ were mapped on rice chromosomes $1,4,12,3,1$ and 7 by morphological markers, respectively (Khush and Kinoshita 1991). $r l 7$ to $r l 12, r l 14$ and $r l(t)$ were located on chromosomes $2(r l(t)$, Shao et al. 2005a), 5 ( $r l(7)$, Li et al. 1998; $r l(8)$, Shao et al. 2005b), 7 ( $r l 11$, Shi et al. 2009), 9 ( $r l 9$, Yan et al. 2008; rl10, Luo et al. 2007), and 10 (rl12, Luo et al. 2009; rl14, Fang et al. 2012), respectively. However, only $r l 9$ and rl14 were cloned and analyzed in detail.

There are some transcription factors which were demonstrated being involved in controlling leaf rolling. $R L 9$, an orthologue of Arabidopsis KANADIs, encodes a Glycoprotein A Repetitions Predominant (GARP) protein and mainly expresses in roots, leaves and flowers. Subcellular localization indicated that $R L 9$ acts as a putative transcription factor due to localizing in the nucleus (Yan et al. 2008). OsMYB103L encodes an R2R3-MYB transcription factor and is localized in the nucleus with transactivation activity. Over-expression of OsMYB103L results in a rolled leaf phenotype. In contrast, knockdown of this gene leads to reduced cellulose content and mechanical strength in leaves (Yang et al. 2014). OsZHD1 is a zinc finger homeodomain class homeobox transcription factor, which exhibits a constitutive expression pattern in wild type (WT) and accumulates in the developing leaves and panicles. Over-expression of OsZHD1 and its homolog OsZHD2 causes the abaxial leaf curling with increased number and abnormal arrangement of bulliform cells (Xu et al. 2014). SHALLOT-LIKE 1 (SLL1) encodes a SHAQKYF class MYB family transcription factor which belongs to the KANADI family and sll1 mutant displays extremely incurved leaves because of the defective development of sclerenchymatous cells on the abaxial side. Further study indicated that SLL1 deficiency leads to abnormal programmed cell death of abaxial mesophyll cells and suppresses the development of abaxial features. However, phloem development on the abaxial side is stimulated and bulliform cell and sclerenchyma development on the adaxial side are both suppressed by enhanced SLL1 expression (Zhang et al. 2009).

In addition, some other genes found in rice mutant also play key roles in controlling leaf rolling. For example, narrow and rolled leaf 1 ( $\mathrm{rl} l 1$ ) encoding a cellulose synthaselike D4 protein is characterized by a phenotype of narrow and rolled leaves (Wu et al. 2010). ADAXIALIZED LEAF 1 (ADL1) encodes a plant-specific calpain-like cysteine proteinase orthologous to maize DEFECTIVE KERNEL1 and adl1 mutant shows abaxially rolled leaves (Hibara et al. 2009). OsAGO7 including the PAZ (Piwi/Argonaute/Zwille) and Piwi conserved domains belongs to the Argonaute (Ago) family and could be orthologous to the Arabidopsis thaliana Ago7 gene. Over- expression of this gene leads to upward curling of the leaf blade (Shi et al. 2007). SEMIROLLED LEAF 1 (SRL1) is located at plasma membrane and predicted to be a putative glycosylphosphatidylinositolanchored protein. srl1 mutant exhibits adaxially rolled leaves due to the increased number of bulliform cells at the adaxial cell layers. Further study showed that SRL1 can inhibit the formation of bulliform cells by regulating the expression of genes encoding vacuolar $\mathrm{H}^{+}$-ATPase subunits and $\mathrm{H}^{+}$-pyrophosphatase negatively (Xiang et al. 2012). LEAF INCLINATION 2 (LC2) encodes a vernalization insensitive 3-like protein which plays an important role in regulating leaf inclination and mediating hormone effects and $l c 2$ mutants have enlarged leaf angles and abaxial leaf curling (Zhao et al. 2010). ABAXIALLY CURLED LEAF 1 ( $A C L 1)$ encodes a protein containing unknown conserved functional domains and over-expression of $A C L 1$ and its homolog ACL2 induces abaxial leaf curling (Li et al. 2010). Most recently, a new gene called SRL2 has been identified and cloned. This gene encodes a novel plant-specific protein of unknown biochemical function. srl 2 mutant has incurved leaves due to the presence of defective sclerenchymatous cells on the abaxial side of the leaf and displays narrow leaves and reduced plant height. Double mutant analysis indicated that $S R L 2$ and $S L L 1 / R L 9$ function in different ways to regulate abaxial-side leaf development (Liu et al. 2016). At last, ROLLED and ERECT LEAF 1 (REL1) encoding a novel no known protein is related to the coordination of brassinosteroid (BR) signaling transduction. Also, rel1 mutant displays rolled and erect leaf and over-expression of REL1 in WT causes a phenotype similarity to that of the dominant rel1 mutant. However, down-regulation of the REL1 gene in the rel1 mutant restores the mutant phenotype (Chen et al. 2015). Considering the similar phenotype as to rell, we named our mutant as rel2.

In eukaryotes, a number of gene families that encode functionally uncharacterized protein were identified as domain of unknown function (DUF) and evolutionary 
conservation suggested that many DUFs have important functions (Goodacre et al. 2014; Wang et al. 2014). Some "Domains of Unknown Function" (DUFs) or "Uncharacterized Protein Families" (UPFs) in Pfam database have been analyzed for both structure and function by computational structural genomics approach (Betman et al. 2010; Goodacre et al. 2014; Mudgal et al. 2015). However, only few of them were determined in detail.

In the present study, we identified a rolling and erect leaf mutant and isolated the control gene by using mapbased cloning strategy. Then, the subcellular localization and expression profiles of the control gene were investigated. The results obtained here provide a new important reference for understanding the mechanism of rolling leaf blades in rice.

\section{Results}

Phenotypes of rel2

The mutant was isolated from $\mathrm{M}_{2}$ generation of rice cultivar Nipponbare (Oryza sativa L. japonica) by mutagenesis with ethyl methanesulfonate (EMS), and was named as rolled and erect leaf 2 (rel2) mainly based on its abnormal phenotypes of leaves. Compared with the WT, the rel2 mutant plants have adaxially rolling and erect leaves which lead to erect architecture of rice plants. During the early seedling stage, the phenotype of rel2 mutant is becoming different from that of WT. As the rice grows, significant phenotypic differences could be distinguished from the two type plants. Figure 1a, b shows the gross morphology of WT and rel2 mutant at tillering stage and heading stage, respectively. In contrast

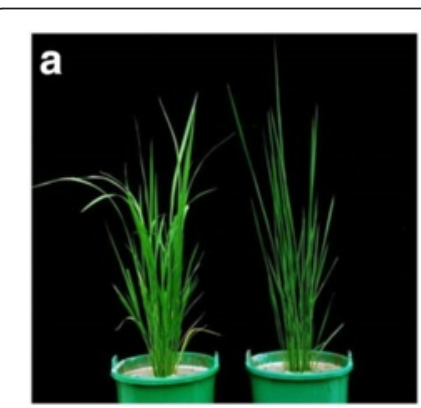

f
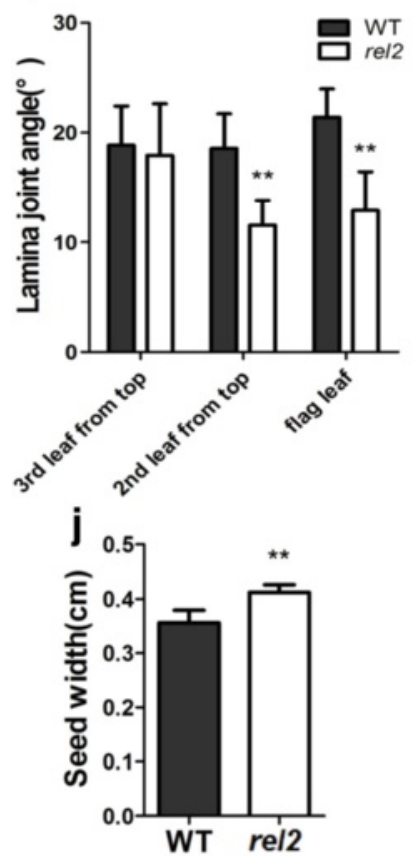

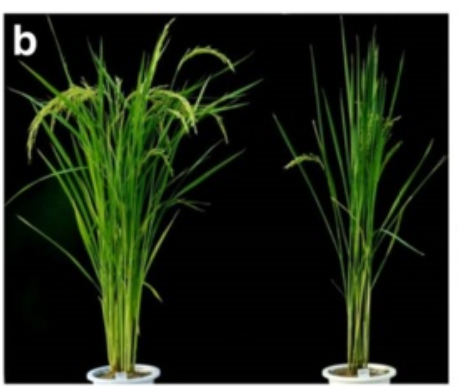

g
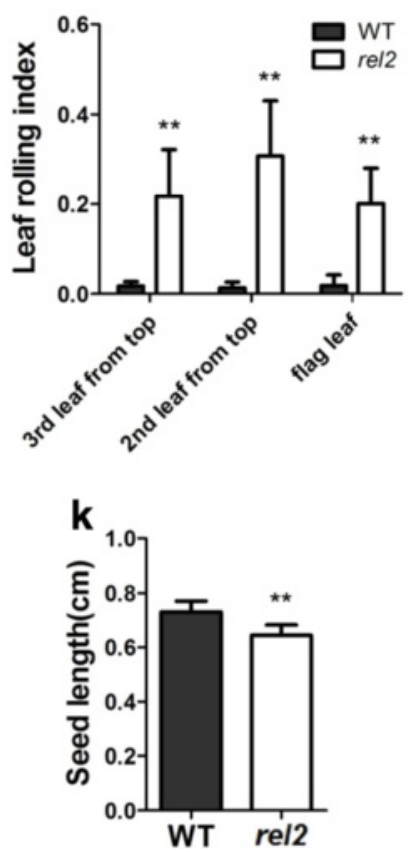
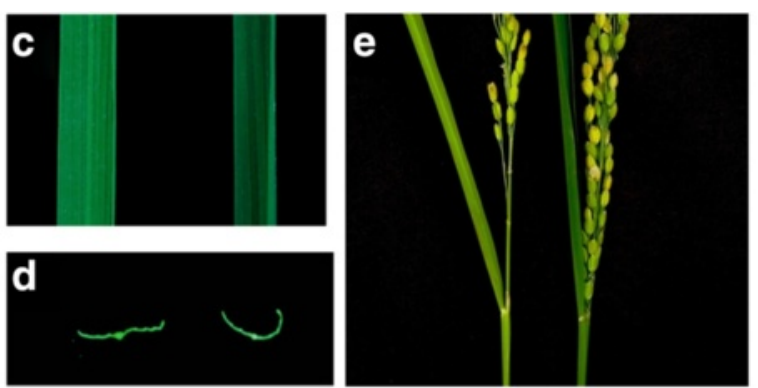

h

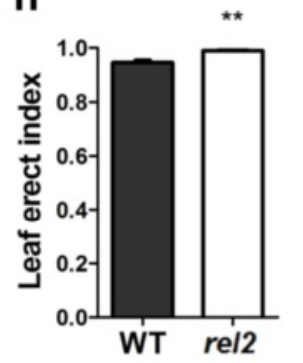

i

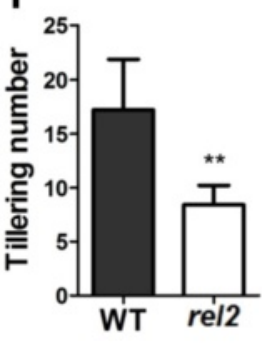

Fig. 1 Characterization of WT and rel2 mutant. a, b Morphology of WT (left) and rel2 mutant (right) at tillering stage and heading stage, respectively. c Morphology of second leaf from the top of WT (left) and rel2 mutant (right) at heading stage. $\mathbf{d}$ Transverse section of the middle part of the second leaf from the top of WT (left) and rel2 mutant (right) at heading stage. e The display of angle between panicle and the flag leaf of WT (left) and rel2 mutant (right). f-k Statistical analysis of lamina joint angle, LRI, LEl, tillering number, seed length and seed width. At least 20 samples of WT and rel2 mutant were measured for each. The values are shown as mean \pm SD. Double asterisk (**) indicates that the difference between the WT and rel2 is statistically significant at $P<0.01$. I Morphology of grains with husk and without husk of WT (down) and rel2 mutant (up) in every comparison 
to the WT, all leaves of rel2 exhibit adaxial rolling (Fig. 1c, d). The rel2 mutant also shows erect growth of two top leaves, owing to reduced lamina joint angle (Fig. 1e, f). The leaf rolling index (LRI) and the leaf erect index (LEI) are significantly increased in rel2 mutant (Fig. 1g, h). In addition, the rel2 mutant also exhibits other abnormal phenotypes, such as reduced tillering number, round grains, reduced number of grains per main panicle (Fig. 1i to l, Table 1). Since all the leaf blades in rel2 mutant plants display darker green leaf phenotype during almost all the growth and development stages, the pigment contents in leaves were also investigated here. The results showed that chlorophyll a $(\mathrm{Chl}$ a) and chlorophyll b (Chl b) contents in mutant leaves are obviously higher than those in WT (Fig. 2a). Even more, the mutant's net photosynthetic rate is decreased whereas its transpiration rate is slightly increased compared with the WT (Fig. 2b, c). Also the number of adventitious roots is significantly less than that of WT. Shorter adventitious roots can also be observed in the rel2 mutant plants (Additional file 1: Figure S1). These observations indicated that the rel2 mutant has multiple morphological defects.

\section{Abnormal Bulliform Cell Number, Size and Arrangement in rel2 Leaf Blades}

Considering the important roles of bulliform cells in determining leaf flatting in rice (Xiang et al. 2012), an analysis of free-hand cross section was carried out in present study. Compared with that of WT, more bulliform cells are observed on adaxial epidermis of rel2 leaf blades (Fig. 3a, b). In the WT leaf blades, bulliform cells are arranged in groups of $5 \pm 1$ cells, with the middle cells larger than those on either side; whereas in the rel2 mutant, bulliform cells are arranged in groups of $8 \pm 1$ cells, with middle cells as small as those of other cells (Fig. 3a, b). Statistical analysis revealed a significant increase of bulliform cell number in rel2 mutant (Fig. 3c). Moreover, we found that the bulliform cells are arranged

Table 1 Comparison differences of some key agronomic traits between WT and rel2 mutant

\begin{tabular}{llc}
\hline Traits & NIP & rel2 \\
\hline The number of grains per panicle & $128 \pm 18$ & $58 \pm 6^{* *}$ \\
Fertility rate (\%) & $88.3 \pm 3.9$ & $69.7 \pm 6.2^{* *}$ \\
1,000-grain weight (g) & $24.8 \pm 0.2$ & $26.7 \pm 0.4^{* *}$ \\
Plant height (cm) & $94.5 \pm 4.0$ & $72.8 \pm 2.7^{* *}$ \\
Panicle length (cm) & $22.0 \pm 1.9$ & $16.9 \pm 1.5^{* *}$ \\
Flag leaf length (cm) & $29.7 \pm 4.0$ & $34.8 \pm 6.3^{* *}$ \\
Second leaf length (cm) & $38.3 \pm 4.8$ & $46.8 \pm 4.9^{* *}$ \\
Third leaf length (cm) & $37.3 \pm 4.8$ & $39.1 \pm 4.1$ \\
\hline
\end{tabular}

The values were shown as mean \pm SD $(n \geq 20)$. Double asterisk $(* *)$ indicates that the difference between the WT and rel2 is statistically significant at $P<0.01$

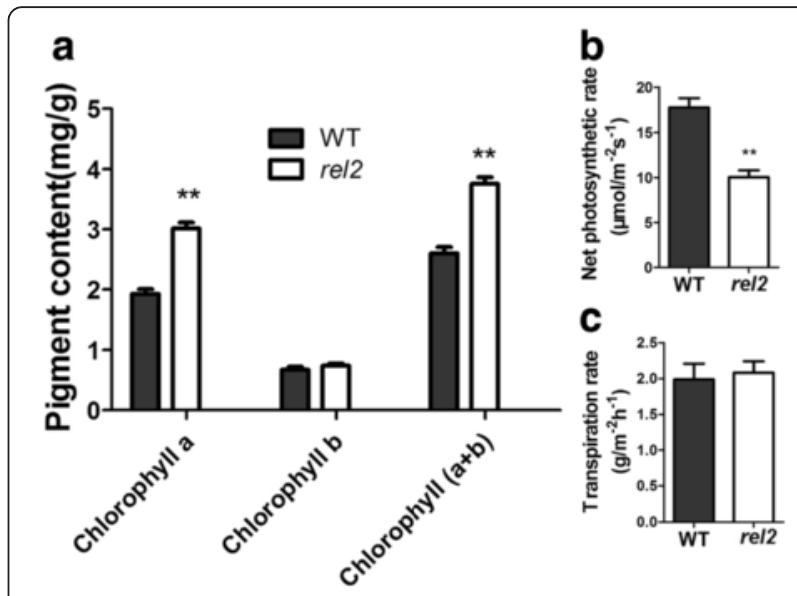

Fig. 2 Characterization of pigment content and photosynthetic rate of rel2 mutant. a Pigment contents of third leaf from the top at heading stage. $\mathbf{b}, \mathbf{c}$ Comparison of net photosynthetic rate and transpiration rate between $\mathrm{WT}$ and rel2 mutant. Pigment contents data are mean \pm $\mathrm{SD}(n=3)$. Net photosynthetic rate and transpiration rate data are mean \pm SD $(n \geq 15)$. Double asterisk $\left.*^{*}\right)$ indicates that the difference between the WT and rel 2 is statistically significant at $P<0.01$

with "U" shape in WT, whereas the bulliform cells of rel2 mutant are arranged with "V" shape (Fig. 3a, b). The depth of bulliform cells is also decreased in rel2 leaf blade as compared to the WT (Fig. 3d). These results indicated that the rolling leaf phenotype should result from the reduced size of middle bulliform cells and "V" shape arrangement of bulliform cell region.

\section{Map-based Cloning of REL2 Gene}

In order to isolate REL2 by map-based cloning strategy, a genetic population was constructed by crossing rel2 mutant with an indica rice cultivar, Kasalath. All $\mathrm{F}_{1}$ hybrids derived from the cross showed normal phenotype, similar to that of Kasalath. In the $\mathrm{F}_{2}$ population, we planted 200 individuals, and identified 142 normal plants and 58 rel2 plants, respectively. The segregation ratio is just fitted to $3: 1\left(\chi^{2}=0.812<\chi_{0.05}^{2}=2.85\right)$, indicating that the rel2 phenotype is controlled by a single recessive nuclear gene.

Using bulked segregant analysis (BSA) method (Michelmore et al. 1991), REL2 gene is showed to link with inset and deletion (InDel) marker R10M40 on rice chromosome 10 (data not shown). A preliminary mapping of REL2 was conducted by genotyping of $94 \mathrm{~F}_{2}$ mutant individuals with simple sequence repeat (SSR) markers near R10M40. Genetic mapping of the target gene revealed that REL2 is linked with the SSR markers at the long arm of chromosome 10 (Fig. 4a). For fine mapping of $R E L 2$, a series of InDel and single nucleotide polymorphism (SNP) markers were newly developed based on the genome sequence differences between Nipponbare and Kasalath (Fig. 4b, c). Genotyping of 

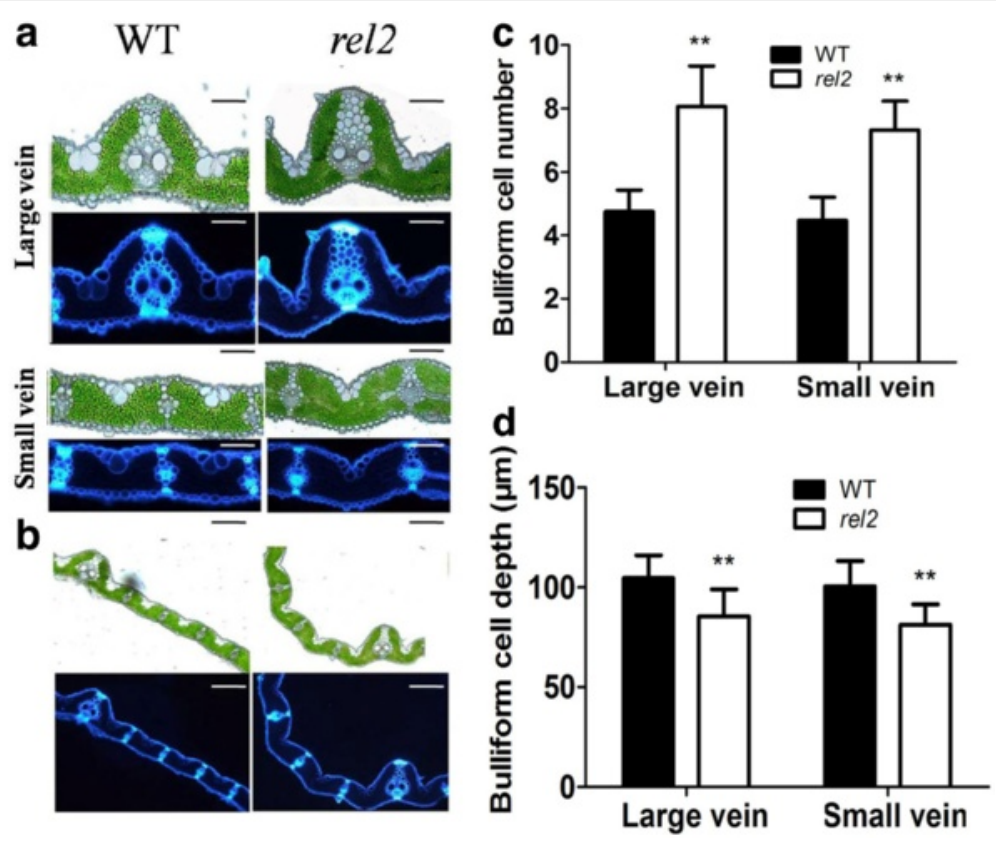

Fig. 3 Histological analysis of the leaf blades between WT and rel2 mutant. a Transverse section of large vein and small vein at the middle of the third leaf from the top at heading stage, Bars $=100 \mu \mathrm{m}$. b Transverse section of leaf blades at the middle of the third leaf from the top at heading stage, Bars $=200 \mu \mathrm{m}$. c Statistics analysis of the number of bulliform cells besides large veins and small veins between WT and rel2 mutant, data are mean \pm SD $(n \geq 10)$. $\mathbf{d}$ Statistics analysis of the depth of bulliform cells on the sides of large veins and small veins between WT and rel2 mutant, data are mean \pm SD $(n \geq 10)$. Double asterisk $\left(^{*}\right.$ *) indicates that the difference between the WT and rel2 is statistically significant at $P<0.01$

$882 \mathrm{~F}_{2}$ mutant individuals revealed that $R E L 2$ is located between SNP markers SN22625 and SN22660, and cosegregated with SN22636 and SN22653 (Fig. 4c). Therefore, the REL2 was mapped to a 35-kb genomic region by SN22625 and SN22660. According to the Rice Annotation Project Database, there are six genes annotated in the 35-kb region (Fig. 4d). A qRT-PCR analysis of all the genes in this region revealed that there is no difference at mRNA level between WT and rel2 mutant (data not shown). We then sequenced all the genes of WT and rel2 mutant with genomic DNA as template, and only found that rel2 mutant has three sequence mutations in locus Os10g0562700, including a 4-bp deletion at 5'UTR and two nucleotide substitutions at open reading frame (ORF) region (Fig. 4e). In fact, the mRNA level of Os10g0562700 has no obvious difference between WT and rel2 mutant (Additional file 2: Figure S2A, B), indicating that the 4-bp deletion in 5'-UTR in rel2 mutant does not affect its transcription expression level. However, the mutation of two nucleotide substitutions in the ORF region causing amino acid substitutions $\left(\mathrm{Cys}^{3}\right.$ to $\mathrm{Tyr}^{3}, \mathrm{Val}^{14}$ to $\mathrm{Met}^{14}$ ) should lead to loss of REL2 function in the mutant. Therefore, the locus Os10g0562700 should be the target gene, REL2. To confirm whether the REL2 disruption resulted in the abnormal leaves, calli induced from rel2 mutant seeds were transformed via Agrobacterium tumefaciens with p35S-1301-REL2, a construct with the full length of REL2 ORF driven by a CaMV35S promoter. The positive plants were detected by GUS array and RT-PCR analysis. In order to know whether the mutant phenotype can be rescued, 23 independent transgenic lines were identified by observing the phenotype of leaves at early tillering stage. The results showed that rolling leaves of the transgenic plants are rescued and the phenotype of the leaves is just as the same to WT (Fig. 5a, b). Also, the results from RT-PCR analysis of transgenic plants showed that the mutant plants could be complemented by the over-expression of REL2 (Fig. 5c), indicating that the normal REL2 protein expression restored the mutant phenotype. These results indicated that the mutant phenotype should be caused by the abnormal function of REL2 protein.

In order to get more information about the REL2 gene, bioinformatics analysis was carried out. High similarity of protein sequences were selected for bioinformatics analysis. After that, a multiple sequences alignment was carried out and evolutionary tree was constructed. The results showed that the DUF630 and DUF632 domains in rice are highly conservative and always together and exhibit relatively close genetic relationship with the domains from Setaria italic, Sorghum bicolor and Zea mays while these two DUF domains were not close with those from Arabidopsis thaliana (Fig. 6a, b). However, all the protein sequences selected have not been studied in detail and their functions are unknown yet, so we concluded that REL2 is a DUF domains contained unknown function protein. 


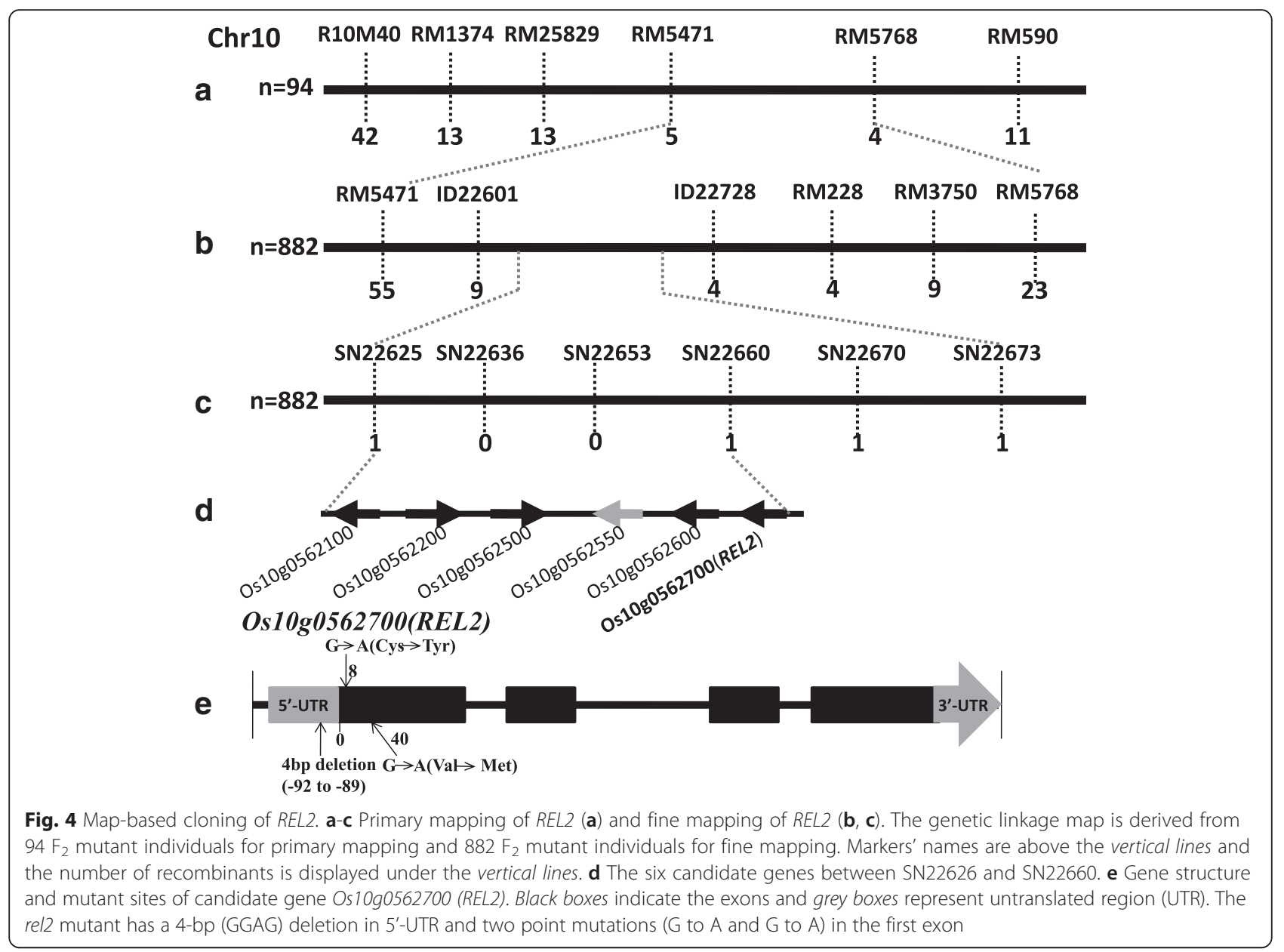

\section{Expression Patterns of REL2 and Subcellular Localization} of the Protein

In order to investigate the expression pattern of REL2, total RNA was extracted from various tissues at different stages of wild-type rice. The expression level in roots at heading stage was set to 1 . The results showed that the level of REL2 transcription is highest in leaves at seedling stage. Also, the transcription level is relatively high in the $1^{\text {st }}$ leaf blades (the top leaf blades) at tillering stage, the $1^{\text {st }}$ leaf blades at booting stage and panicle before flowering at heading stage. However, there is no expression at the $2^{\text {nd }}$ leaf sheaths (the second leaf sheath from the top leaf sheath) at tillering, booting and heading stages. Meanwhile, the transcription level of REL2 in other tissues is quite low (Fig. 7). These results suggested that REL2 is dominantly expressed in the relatively younger leaf blades.

To investigate the location of REL2 protein in cells, full length complementary DNA (cDNA) of REL2 without stop condon was introduced into the p35S-GFP expression vector. To determine the roles of the two DUF domains in the location of REL2 protein, both
DUF630 and DUF632 domain sequences were cloned into the $p 35 S$-GFP expression vector, respectively. The fused genes were injected into tobacco and the fluorescent signal was detected after transformation. As can be seen, the fluorescent signal from the infection with the full length cDNA of REL2 was observed in the plasma membranes of the cells from both tobacco leaves and tobacco protoplasts (Fig. 8a, b), indicating that REL2 is a plasma membrane located protein. However, the two infections with the gene pieces of containing DUF630 and DUF632 domains separately, exhibited no specific localizations in the tobacco leaf cells and protoplasts, implying that both the two domains separated peptides have no plasma membrane localization in the cells (Fig. 8c, d).

\section{rel2 Mutation Affects the Expression of Several Leaf Shape Regulation Genes}

To determine the expression relationship of REL2 with the leaf shape regulation associated genes, a total of eighteen genes were selected to be analyzed by qRT-PCR (Fig. 9). Total RNA was extracted from young leaves of 


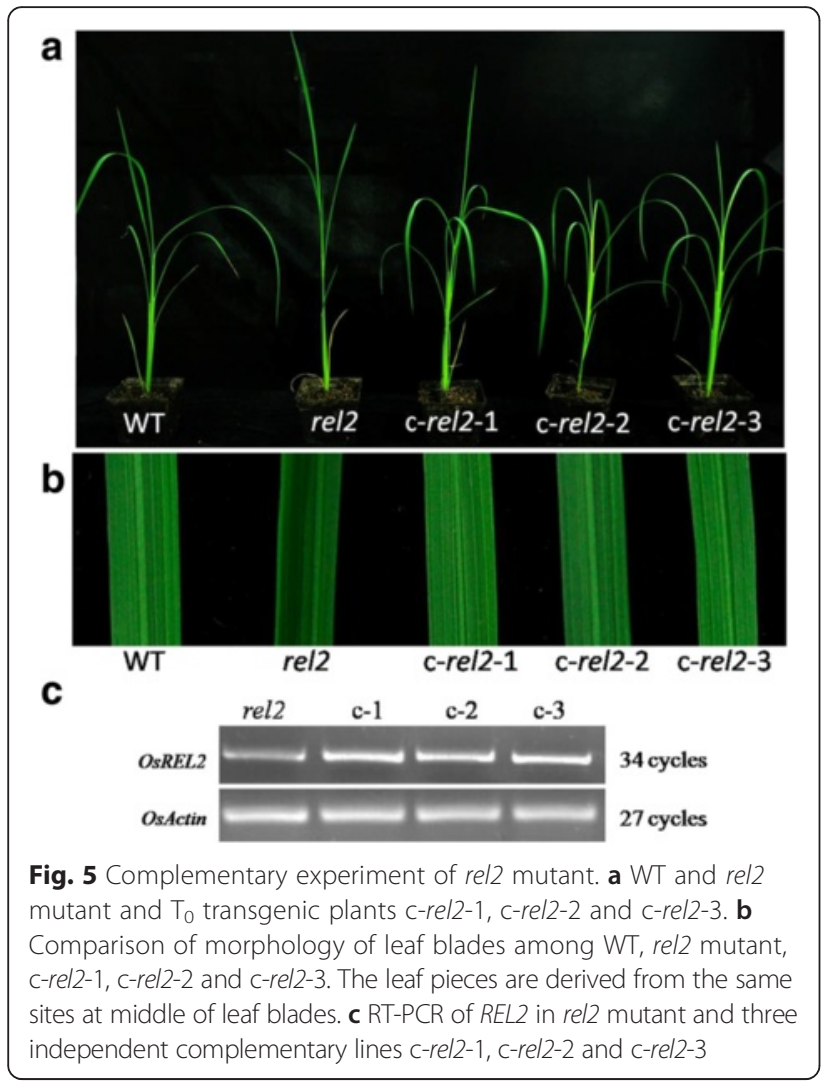

both WT and rel2 mutant at seedling stage. The results showed that Rice outermost cell-specific gene 5 (Roc5) (homeodomain leucine zipper class IV gene) (Zou et al. 2011), $A D L 1$ (plant-specific calpain-like cysteine proteinase gene) (Hibara et al. 2009) and OsBAK1 (a BR signaling related gene) (Li et al. 2009) are significantly up-regulated in rel2 mutant. In contrast, genes called SLL1 (a KANADI transcription factor) (Zhang et al. 2009), NARROW LEAF 1 (NAL1) (a gene encoding a plant-specific protein affecting cell division) (Qi et al. 2008; Jiang et al. 2015), NARROW LEAF 7 (NAL7) (a flavin-containing monooxygenase gene) (Fujino et al. 2008), OsZHD1 and OsZHD2 (zinc finger homeodomain class homeobox transcription factors) (Xu et al. 2014), ROLLED LEAF 14 (RL14) (a 2OGFe (II) oxygenase family protein gene) (Fang et al. 2012), $N R L 1$ (a cellulose synthase-like $\mathrm{D} 4$ protein gene) (Wu et al. 2010), OsAGO7 (an Argonatue family gene) (Shi et al. 2007), RL9 (a GARP protein gene) (Yan et al. 2008), REL1(encoding a novel no known protein) (Chen et al. 2015), LC2 (a vernalization insensitive 3-like protein gene) (Zhao et al. 2010), ACL2 (a gene containing unknown conserved functional domains) ( $\mathrm{Li}$ et al. 2010) and OsMYB103L (an R2R3-MYB transcription factor gene) (Yang et al. 2014) are down-regulated significantly in rel2 mutant. These findings suggested that there might be a functional association between REL2 and those genes in regulating leaf morphological development of rice. By contrast, SRL1 and ACL1 have no expression changes in rel2 mutant, indicating that the two genes may not have functional relationship with REL2 (Fig. 9).

\section{Discussion}

The Leaf Rolling Phenotype of rel2 should Result from the Abnormal Development of Bulliform Cells

There are several factors leading to leaf rolling in plants. Generally, leaf rolling is caused by the water loss of bulliform cells on adaxial epidermis in rice (O'Toole and Cruz 1980). This indicated that the number and area even the phenotype of bulliform cells may have effects on leaf rolling. Also, some other environment factors can affect leaf rolling such as high air temperature and strong sun light (Kidner and Timmermans 2007). Because the large and highly vacuolated vascular bundles bulliform cells on the adaxial epidermis of leaves participate in the regulation of leaf rolling (Xiang et al. 2012), uncovering the genes related to bulliform cells development is a necessary way to figure out the mechanism of leaf rolling. Until to now, genes associated with the development of bulliform cells have been studied. For example, srl1 is involved in the regulation of leaf rolling and srl 1 mutant exhibits adaxially rolled leaves due to the increased numbers of bulliform cells at the adaxial cell layers. Further study showed that SRL1 gene regulates leaf rolling by inhibiting the formation of bulliform cells through negatively regulating the expression of genes encoding vacuolar $\mathrm{H}^{+}$-ATPase subunits and $\mathrm{H}^{+}$-pyrophosphatase (Xiang et al. 2012). This mechanism is relatively clear and confirms that the number of bulliform cells is indeed to affect the leaf rolling. Also, the mutant of $A D L 1$, ACL1, NAL1, ROC5 and OsZHD1 genes could lead to rolling leaves by changing the number and area of bulliform cells in adaxial leaf blades (Fujino et al. 2008; Hibara et al. 2009; Li et al. 2010; Zou et al. 2011; Xu et al. 2014). In the present study, the rel2 mutant also shows changed phenotype of bulliform cells. The number of bulliform cells is obviously increased, but the size of middle bulliform cells is significantly decreased in leaf blades of rel2 mutant as compared to WT. In addition, the rel2 mutant leaf blades have reduced depth of bulliform cell region and the plant architecture is more erect by the straight leaves due to the leaf rolling (Fig. 1a, b). Even more, the expression patterns of $R E L 2$ indicated that REL2 has relatively higher expression in leaf blades (Fig. 7) which is consistent with the rel2 mutant phenotype of leaf blades. The changes of bulliform cells in leaf blades may indicate that REL2 might be related with the development of bulliform cells. The higher expression of REL2 in panicle (before flowering) is also consistent with the changed traits such as seed shape, grains number per panicle. Although many studies showed that the leaf rolling can contribute to the photosynthetic efficiency (Yuan 1997; Zhang et al. 2009), the 


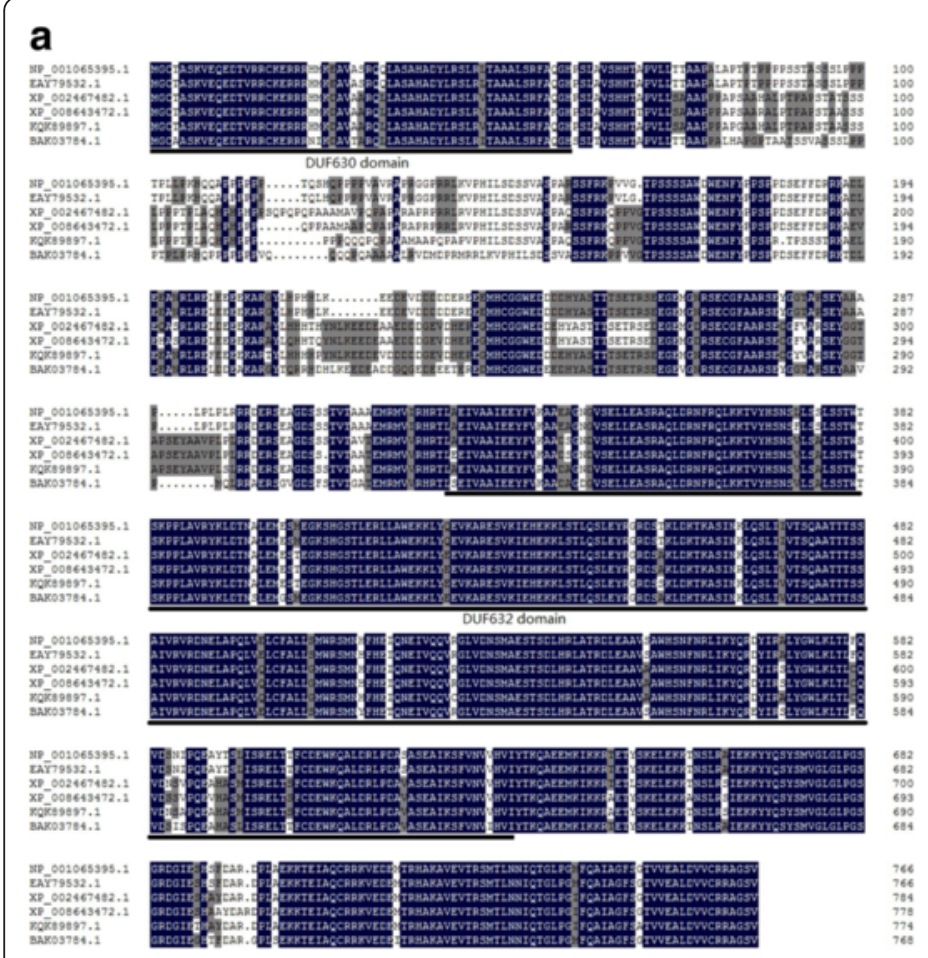

\section{b}

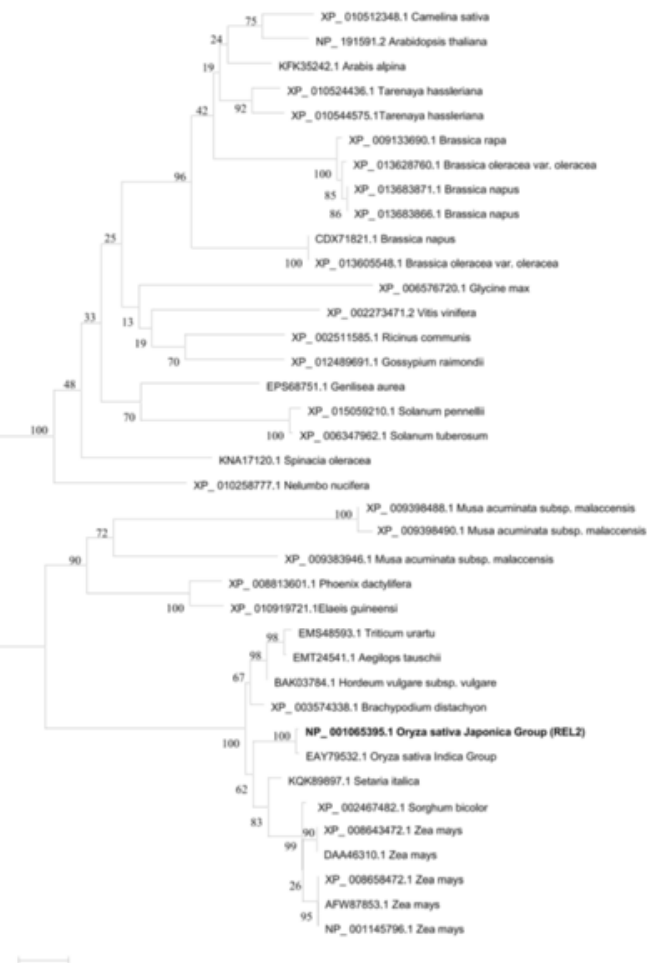

ees

Fig. 6 Multiple sequences alignment of REL2 with its highly similar protein sequences and phylogenic tree. a Multiple sequences alignment of Oryza sativa Japonica Group [GenBank accession number: NP_001065395.1, REL2], Oryza sativa Indica Group [GenBank accession number: EAY79532.1], Sorghum bicolor [GenBank accession number: XP_002467482.1], Zea mays [GenBank accession number: XP_008643472.1], Setaria italic [GenBank accession number: KQK89897.1] and Hordeum vulgare subsp. vulgare [GenBank accession number: BAK03784.1]. The amino acids showing identity are shaded dark blue, whereas similar amino acids are shaded grey. $\mathbf{b}$ Phylogenic tree of REL2 and its highly similar proteins. The protein sequences are displayed as GenBank accession number and species name

net photosynthetic rate of rel2 is actually decreased as compared with that of WT (Fig. 2b), indicating a complicated mechanism involves in the functions of REL2. This needs to be further elucidated.

\section{DUF630 and DUF632 Domains may be Together to Implement their Function}

As shown in Fig. 6a, the REL2 protein contains a DUF630 domain at the N-terminus and a DUF632 domain at the Cterminus. The DUF630 domain containing 59 amino acids was annotated that it was sometimes found at the $\mathrm{N}$ terminus of putative plant bZIP protein and structural modeling suggested that this domain may bind nucleic acid. Meanwhile, the DUF632 domain containing 309 amino acids was described as a leucine zipper even though there was no experimental evidence supporting that (http://blast.ncbi.nlm.nih.gov/). However, the subcellular localization analysis of the entire protein sequence of REL2 in tobacco indicated that this protein is located on plasma membrane (Fig. 8a, b). But since no transmembrane domains were found in its animo acid sequence, REL2 may encode a plasma membrane anchored protein. Apart from this, the peptides containing DUF630 or DUF632 alone exhibit no special localization in tobacco cells (Fig. 8c, d). Considering the evolutionary conservation of DUF domains (Goodacre et al. 2014) and the co-evolution of DUF630 and DUF632, the results obtained here clearly indicated that the two DUF domains should be together to implement their functions. Since that all the protein sequences from different species were not studied in detail, our current study provides a primary reference for the function of DUF630 and DUF632 domains in plants.

\section{REL2 may Regulate Leaf Shape by Coordination with Multiple Biological Factors}

Multiple biological factors might participate in REL2 controlled leaf rolling. It has been suggested that plant hormones play important roles in plant growth and development. For example, BR is vital for plant growth and development, especially in the regulation of leaf morphology and a rolled or erect leaf phenotype can always be observed by the BR-deficient mutants (Bishop and Yokoka 2001; Hong et al. 2004). For instance, the rel1 


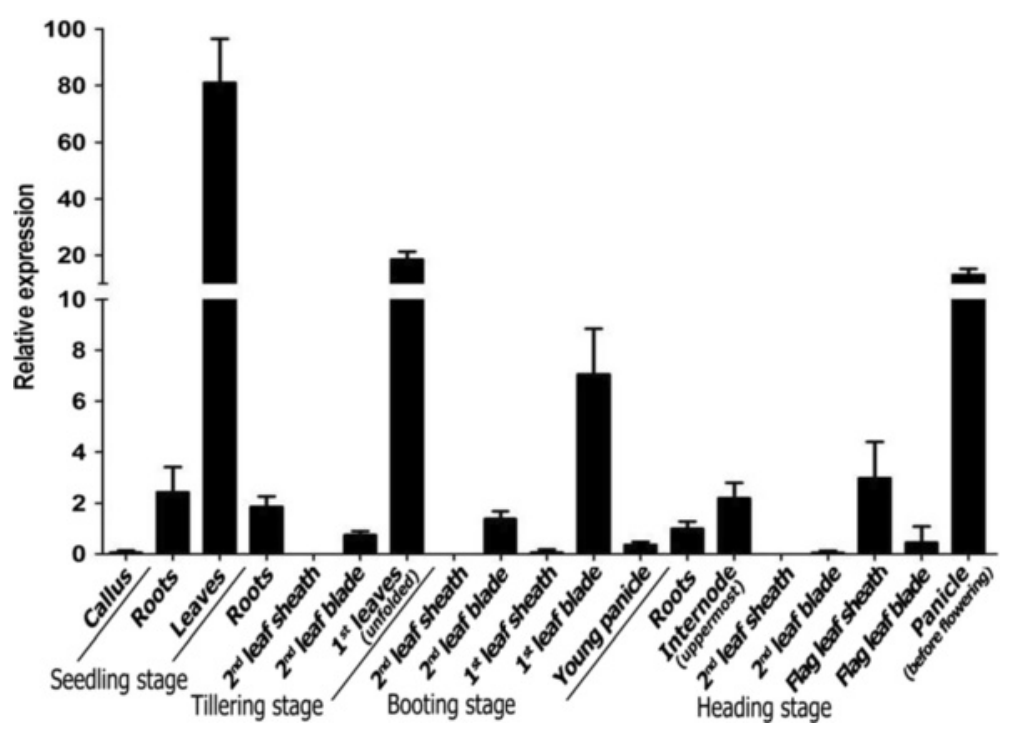

Fig. 7 qRT-PCR analysis of the expression pattern of REL2. Total RNA was extracted from various tissues from callus and WT plants. Rice Actin1 gene was used as a control. The expression of REL 2 in roots at heading stage was set to 1 . The $1^{\text {st }}$ leaf blades or $2^{\text {nd }}$ leaf blade mean the position of leaf blades or leaf sheaths. From up to down of a rice plant, the first leaf blade or leaf sheath is the $1^{\text {st }}$ leaf blade or leaf sheath and the second leaf blade or leaf sheath is the $2^{\text {nd }}$ leaf blade or leaf sheath. The values are the mean \pm SEM with three biological replicates

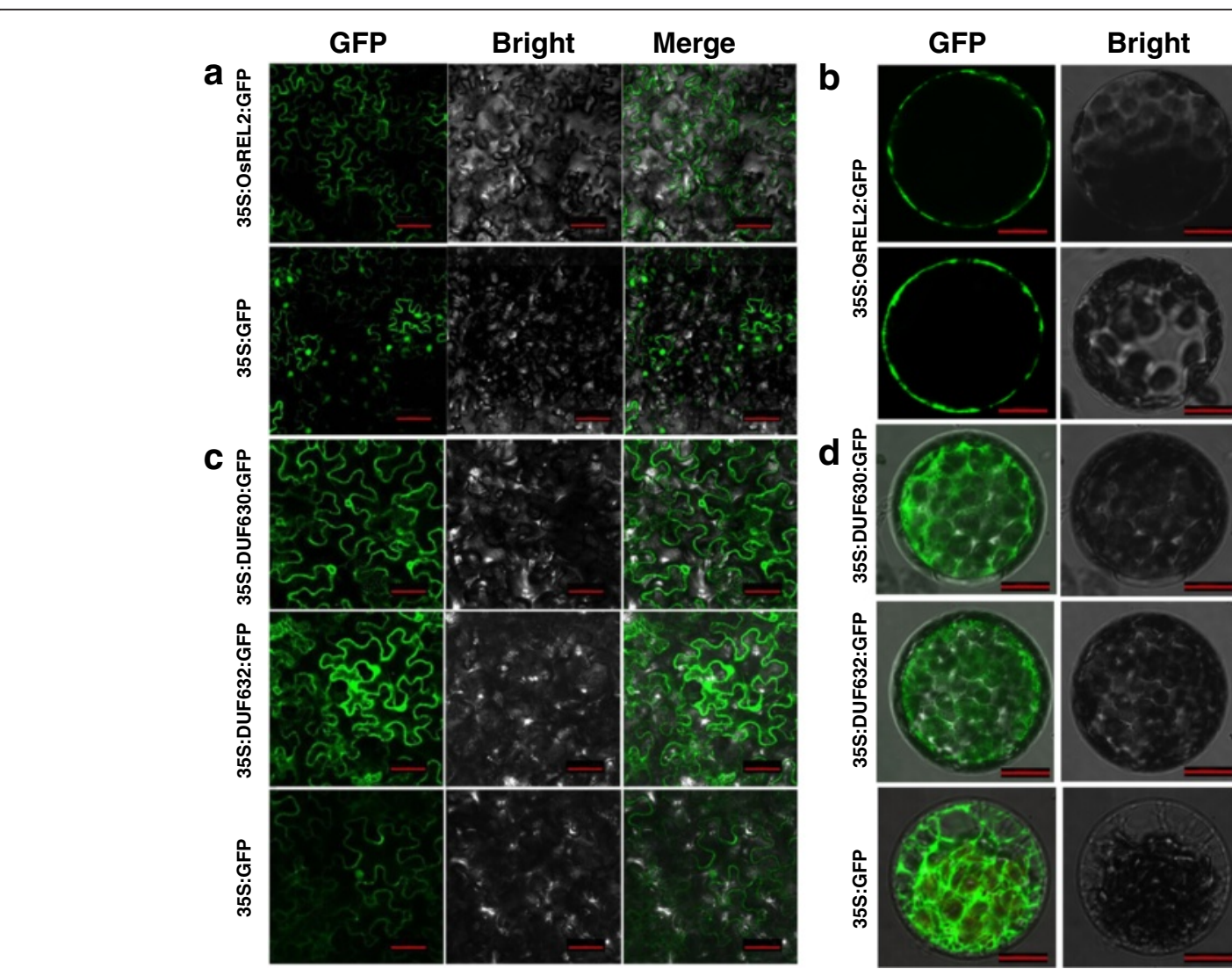

Fig. 8 Subcellular localization of REL2. a Analysis of the subcellular localization of REL2 using a tobacco transient transformation system in the cells of tobacco leaves. Bars $=100 \mu \mathrm{m}$. b Subcellular localization of REL2 with tobacco protoplasts. Bars $=10 \mu \mathrm{m}$. c Subcellular localization of DUF630 and DUF632 in the cells of tobacco leaves. Bars $=50 \mu \mathrm{m}$. d Subcellular localization of DUF630 and DUF632 with tobacco protoplasts. Bars $=100 \mu \mathrm{m}$ 


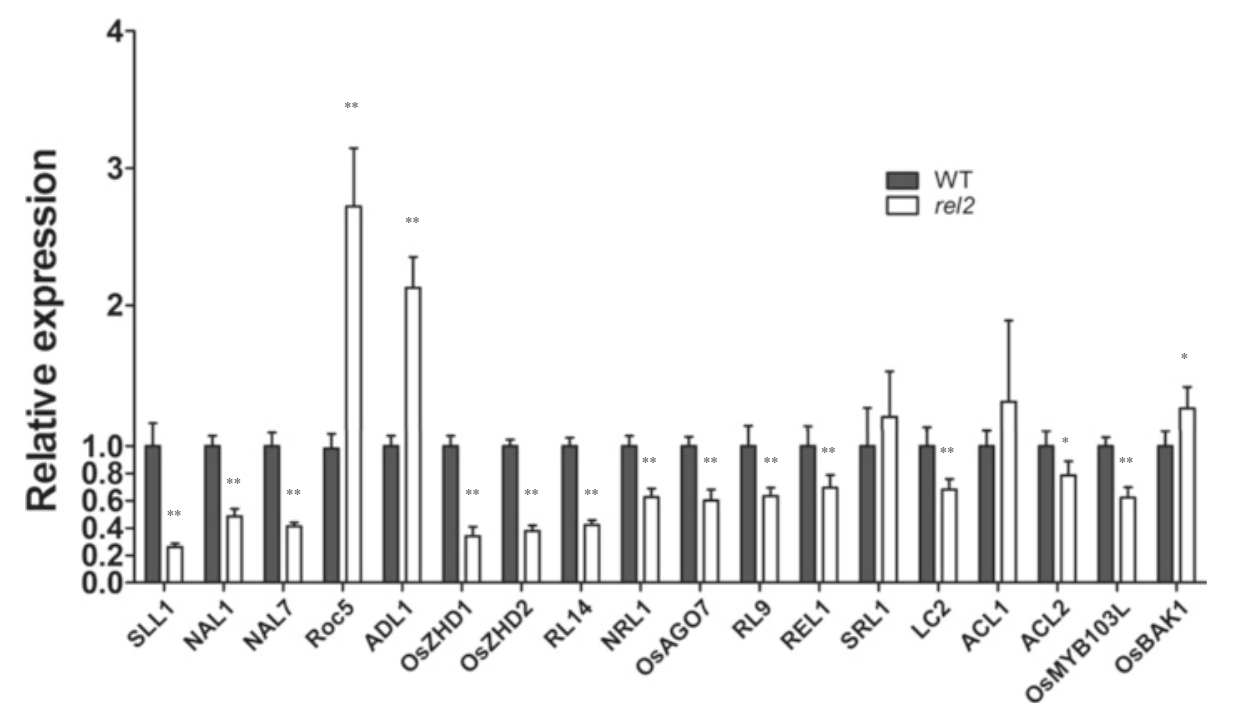

Fig. 9 qRT-PCR analysis of the expression of genes related to leaf shape regulation in rel2 mutant. Total RNA was extracted from leaves of WT and rel2 mutant at seedling stage. Rice Actin 1 gene was used as a control. The values are the mean \pm SEM with three biological replicates. Double asterisk $\left(^{*} *\right.$ indicates that the difference between the WT and rel2 is statistically significant at $P<0.01$. Single asterisk $\left(^{*}\right)$ indicates that the difference between the WT and rel2 is statistically significant at $P<0.05$

mutant has rolled and erect leaves and a yeast two-hybrid screen experiment proved that REL1 involves in the coordination of BR signaling transduction (Chen et al. 2015). However, the results from our leaf inclination experiment with BR showed that there may be no relationship between REL2 gene and BR (data not shown). Another well known hormone which participates in plant growth regulation and development is auxin, acting as a signal for cell division, cell elongation and cell differentiation. Auxin also plays a key role in regulating the leaf primordum at the indeterminate SAM and cell growth in the development of leaves (Kepinski 2006; Tax and Durbak 2006; Fujino et al. 2008). In rice, NAL1 and NAL7 encode a putative trypsinlike serine/cysteine protease and a flavin-containing monooxygenase which displays sequence homology with $Y U C C A$, respectively. Both of them participate in auxin regulation. NAL1 affects vein patterning and polar auxin transport (PAT) and NAL7 has an effect on auxin biosynthesis (Fujino et al. 2008; Qi et al. 2008; Cho et al. 2014). In the present study, we found that the transcription expression of both NAL1 and NAL7 is down-regulated obviously in the rel 2 mutant, indicating that the function of REL2 gene in rice leaf rolling may be related to the auxin regulation also (Fig. 9).

Other biological factors might also participate in REL2-controled leaf rolling. It has been suggested that SLL1 is involved in the development of sclerenchymatous cell on the abaxial side of rice leaves and SLL1 deficiency leads to increased chlorophyll and photosynthesis (Zhang et al. 2009). In rel2 mutant, SLL1 was down-regulated obviously, indicating that $R E L 2$ may have certain relationship with the sclerenchymatous development. In addition, the increased chlorophyll contents but decreased net photosynthetic rate of rel2 mutant further implied that the functions of REL2 in leaf rolling might be related to SLL1. $R L 14$ is a 2OG-Fe (II) oxygenase family protein gene which affects secondary cell wall formation in rice (Fang et al. 2012). Here, we found that its expression was also obviously down-regulated in the rel 2 mutant, suggesting that REL2 may have some relationship with the lignin and cellulose biosynthesis for secondary cell wall formation, also. Moreover, three other genes, ROC5, OsZHD1 and OsZHD2, were found to be up-regulated or down-regulated apparently in rel2 mutant. These three genes were reported affecting the number, size and arrangement of bulliform cells in rice (Zou et al. 2011; Xu et al. 2014). Considering the phenotype of bulliform cells in rel2 also changed significantly, it can be suspected that the functioning of REL2 gene in the formation of bulliform cells might have somewhat linkages with the three genes. $A D L 1$ is a plant-specific calpain-like cysteine proteinase and was proposed to regulate the pattern formation of leaf and embryo in rice (Hibara et al. 2009). Up-regulated of $A D L 1$ in rel2 mutant indicated that REL2 might have function in the pattern formation and embryo, too. Overall, these results suggested that REL2 is a pleiotropic gene and may participate in various biological processes with many other functional genes as discussed above.

To sum up, all of these results suggested that a complicated mechanism might be involved in the leaf rolling control in rice. The function of REL2 in this process needs further studies. 


\section{Conclusions}

A new leaf rolling controlling gene, named REL2, was identified in rice by using the map-based cloning strategy. This gene encodes a DUF630 and DUF632 domains containing protein and its loss of function led to rolling and erect leaves. The rolling leaves were caused by the abnormal development of bulliform cells and the functions of REL2 might involve in multiple biological processes such as bulliform cell development, auxin synthesis and transport, secondary cell wall formation, etc. REL2 is the first discovered DUF domains contained protein which involves in the regulation of leaf morphology in plants.

\section{Methods}

\section{Plant Materials and Growth Conditions}

The rel2 mutant with rolling leaves was isolated from the $\mathrm{M}_{2}$ generation of japonica rice cultivar Nipponbare by EMS treatment (rice seeds were treated with $0.4 \%$ EMS for $8 \mathrm{~h}$ ). The $\mathrm{F}_{2}$ mapping population was generated from a cross between mutant rel2 and normal indica rice cultivar Kasalath. 882 rel2 individuals were identified from the $\mathrm{F}_{2}$ mapping population in total. All plant materials were grown in the paddy field in Hanzhong, Shannxi province, China, in the summer of 2013 and 2014.

\section{Measurement of LEI and LRI}

The plants at heading stage were used for the determination of the leaf erect index (LEI) and leaf rolling index (LRI). For testing LEI, Lsl (the distance between lamina joint and the tip of the leaf blade at stretched situation) and Lnl (the distance between lamina joint and the tip of the leaf blade at natural condition) were measured. For testing LRI, Lw (expand the leaf blade and determine the greatest width) and Ln (the natural distance of leaf blade margins at the same position) were measured. Then the LEI and LRI can be calculated by the following formulas (Shi et al. 2007):

$$
\begin{aligned}
& \operatorname{LEI}(\%)=\mathrm{L}_{\mathrm{nl}} / \mathrm{L}_{\mathrm{sl}} \times 100 \\
& \operatorname{LRI}(\%)=\left(\mathrm{L}_{\mathrm{w}}-\mathrm{L}_{\mathrm{n}}\right) / \mathrm{L}_{\mathrm{w}} \times 100
\end{aligned}
$$

\section{Pigment and Net Photosynthetic Rate Measurement}

$0.2 \mathrm{~g}$ fresh leaves of rice in tillering stage were harvested to extract pigments and the contents of pigments were measured by a spectrophotometer according to the method described previously (Arnon 1949). Simply, leaves were cut into pieces and marinated in $95 \%$ ethanol for $12 \mathrm{~h}$ under dark environment. Then, the pigments were collected by centrifugation and determined with a Spectrophotometer Evolution 300 (Thermo scientific, US) at $665,649 \mathrm{~nm}$, respectively. Three independent samples from different plants of WT and rel2 were used for the analysis. Net photosynthetic rates and transpiration rates were measured at heading stage with the portable photosynthetic $\mathrm{LCPRO}_{+}$instrument (ADC Bioscientific, UK) in the morning between 9:00 and 11:00. The measurement of net photosynthetic and transpiration rates of both groups of WT and rel2 mutants was repeated at least three times on every different plant and at least five plants of each type plant were investigated.

\section{Histological Analysis}

The flag leaves of WT and rel2 were fixed in FAA (Formalin-Aceto-Alcohol) solution for $2 \mathrm{~h}$. Leaf pieces with an area approximately $0.5 \mathrm{~cm} \times 0.3 \mathrm{~cm}$ of WT and rel2 plants at heading stage were hand-sectioned by using a razor blade. The sections of about $20-40 \mu \mathrm{m}$ thickness were chosen to be examined by fluorescence microscopy DMIRB (Leica, Germany). Photographs were taken with a Leica light microscope and digital images were captured by using a DFC300 FX camera (Leica, Germany). At least three independent experiments were carried out for each analysis. Adobe photoshop CS4 software was used to calculate the depth and the number of bulliform cells (Bai et al. 2008).

\section{DNA Extraction and PCR Analysis}

Rice genomic DNA was extracted from fresh leaves using modified CTAB (Hexadecyltrimethy Ammonium Bromide) method (Murray and Thompson 1980) at heading stage when significantly different phenotypes appeared. PCR reaction system was as follows: denaturation at $94{ }^{\circ} \mathrm{C}$ for $10 \mathrm{~min}$; then followed by $32-35$ cycles of $94{ }^{\circ} \mathrm{C}$ for $30 \mathrm{~s}$, $53-58{ }^{\circ} \mathrm{C}$ for $30 \mathrm{~s}, 72{ }^{\circ} \mathrm{C}$ for $30 \mathrm{~s}$, and the final step was extension for $5 \mathrm{~min}$. After that, the PCR products were separated by $8 \%$ polyacrylamide gel electrophoresis and the amplified bands were detected by silver staining.

\section{Map-based Cloning of rel2}

In order to locate the position of the rel 2 on the rice chromosomes, 162 SSR (simple sequence repeat) markers and 37 InDel (insertion and deletion) markers were obtained from the rice GRAMENE database (http:// www.gramene.org/) and (Shen et al. 2004). These markers were distributed evenly on rice 12 chromosomes and polymorphism between Nipponbare and Kasalath was displayed. Two pools (normal pool and mutant pool) were constructed by using equal amount of DNA of WT and $F_{2}$ mutant with 10 individuals for each. The polymorphic markers screened in bulk segregant analysis (BSA) (Michelmore et al. 1991) were used for linkage analysis and molecular mapping. 94 mutant individuals from $\mathrm{F}_{2}$ were used for primary mapping. For fine mapping, a larger population with 882 mutant individuals from $\mathrm{F}_{2}$ was used. All the PCR products were analyzed by $8 \%$ polyacrylamide gel electrophoresis. 


\section{Phylogenetic Analysis}

The full-length amino acid sequence of REL2 was downloaded from National Center for Biotechnology Information (NCBI) and its more than $50 \%$ similarity protein sequences were obtained through a search of NCBI non-redundant protein sequences database (http://blast.ncbi.nlm.nih.gov/Blast.cgi). The alignment of amino acid sequences was carried out by using ClustalX2.0 (Jeanmougin et al. 1998). A neighbor-joining tree was generated by MEGA5.1 software by the bootstrap method with 1,000 replicates (Tamura et al. 2011).

\section{Development of New InDel and SNP Markers}

To confirm the rel2 at a smaller range on the rice chromosomes, new InDel and SNP markers were developed because of the lack of known markers. In order to develop new markers, the japonica rice cultivar Nipponbare genome sequences according to IRGSP (2005) were used as a query to do a BLAST against the whole genome sequences database of indica rice cultivar Kasalath (http:// blast.ncbi.nlm.nih.gov/). Differences of more than two nucleotides were chosen to design InDel markers and single nucleotide polymorphisms were used to design SNP markers. All the new designed markers were validated by PCR analysis and polyacrylamide or agarose gel electrophoresis to acquire the polymorphic markers between Nipponbare and Kasalath. The new InDel and SNP markers were listed in Additional file 3: Table S1.

\section{Sequencing Analysis of the Candidate Region}

To understand the possible functions of candidate genes, the annotation of candidate genes had been referring to the rice GRAMENE database (http://www.gramene.org) and the Rice Annotation Project Database (http://rapdb.dna.affrc.go.jp/viewer/gbrowse/build4/). Furthermore, six pairs of primers were synthesized to amplify the whole gene sequences of Os10g0562100, Os10g0562200, Os10g0562500, Os10g0562550, Os10g0562600 and Os10g05 62700 (Additional file 4: Table S2). Specific DNA fragments amplified by PCR from genomic DNA of WT and rel2 were cloned into pMD19-T vector and then sequenced by Invitrogen Biotechnology Co., Ltd (Shanghai, China). To determine the mutant sites, the specific sequences were used to do a BLAST against the whole genome sequences Nipponbare (http://blast.ncbi.nlm. nih.gov/).

\section{Complementation of the rel2 Mutant}

For functional complementation of rel2 mutant, the full length of WT cDNA of REL2 was cloned into the binary p35S-1301 vector, which contained a hygromycin resistance marker. Calli induced from rel2 mutant seeds was used for transformation with Agrobacterium tumefaciens EHA105 carrying the $p 35 S-1301-R E L 2$ plasmid. The positive plants were identified by GUS array. To determine whether the phenotype of rel2 mutant was recovered by the over-expression of $R E L 2$, the leaves and expression of $R E L 2$ of $\mathrm{T}_{0}$ transgenic lines were investigated.

\section{Subcellular Localization of REL2}

Full length coding sequence of REL2 with eliminated stop condon was cloned into $p 35 S-G F P$ vector. Meanwhile, the full length protein sequence of REL2 was divided into two parts named DUF630 (1AA-314AA) and DUF632 (315AA-767AA), respectively. Both nucleotide sequences of DUF630 and DUF632 were cloned into p35S-GFP vector. The vector $p 35 S-G F P$ without any pieces of REL2 sequence was used as the control. All the vectors were transformed into Agrobacterium tumefaciens (EHA105). The infected Agrobacterium tumefaciens cells were harvested by centrifugation. Then a solution containing $10 \mathrm{mM}$ MES ( $\mathrm{pH} 5.6), 10 \mathrm{mM}$ $\mathrm{MgCl}_{2}$ and $200 \mu \mathrm{M}$ acetosyringone was applied to suspend the Agrobacterium tumefaciens cells to an optical density about 0.8-1.0 OD at $600 \mathrm{~nm}$. After that, the 4week old leaves of Nicotiana benthamiana were infiltrated with the Agrobacterium tumefaciens cells by using a needleless syringe. After growing for 3-4 days, the tobacco leaves were detected by a confocal microscope (AIR, Nikon, Japan). Also, the protoplasts from tobacco leaves which were infiltrated with the infected Agrobacterium tumefaciens cells were separated and observed with the same machine.

\section{RNA Isolation and Gene Expression Analysis}

To investigate the expression patterns of REL2, total RNA was extracted from various tissues of WT plants at different developmental stages using RNAiso ${ }^{\text {Tx }}$ Plus (TaKaRa, Dalian) according to the manufacturer's protocol. For analysis of REL2 cDNA sequence in rel2 mutant, total RNA was extracted from young leaves of WT and rel2 mutant respectively. The extracted RNA was treated with RNase-free DNaseI to eliminate genomic DNA contamination. First strand cDNAs were synthesized from $2.5 \mu \mathrm{g}$ total RNA using the M-MLV reverse transcriptase kit (Transgen biotech, Beijing). Both RT-PCR and qRT-PCR were used to analyze the expression level of REL2/Os10g0562700 in WT and rel2 mutant. The primers were listed in additional file 5: Table S3. qRTPCR was carried out using the real-time PCR master mix (SYBR green, TaKaRa) with the CFX96 machine (Bio-Rad) following the manufacturer's instructions. For analysis of REL2 various tissues expression, a specific fragment was amplified by using primers 5'TGATCAT CGTGACTTCACAGGC-3' and 5'-TCTACCAGACCA CGGACTTGC-3'. Also, to determine the expression levels of some rolling-leaf genes (SLL1, NAL1, NAL7, Roc5, ADL1, OsZHD1, OsZHD2, RL14, NRL1, AGO7, 
RL9, REL1, SRL1, LC2, ACL1, ACL2, OsMYB103L and OsBAK1) in rel2 mutants, qRT-PCR was carried out by using the specific primers listed in Additional file 5: Table S3. The rice Actin1 gene specific primers 5'CGTCAGCAACTGGGATGATATG-3' and 5'-GTGT GGCTGACACCATCACCAG-3' were used as an internal control.

\section{Additional files}

Additional file 1: Figure S1. Morphology of roots between WT and rel2 mutant. A Phenotype comparison of roots between WT and rel2 mutant. B Statistical analysis of the number of adventitious roots among WT and rel2 mutant. The values are the mean $\pm S D(n=10)$. Single asterisk $\left(^{*}\right)$ indicates that the difference between the WT and rel 2 is statistically significant at $P<0.05$. (JPG $150 \mathrm{~kb}$ )

Additional file 2: Figure S2. Analysis of REL2 expression level in WT and rel2 mutant. A RT-PCR analysis of REL2 transcription expression level. $B$ qRT-PCR analysis of REL2 transcription expression level. The values are the mean \pm SEM with three biological replicates. Rice actin1 gene was used as a control. (JPG $36 \mathrm{~kb})$

Additional file 3: Table S1. New developed InDel markers and SNP markers used for mapping. (DOCX $12 \mathrm{~kb}$ )

Additional file 4: Table S2. Primers used for amplifying candidate genes. (DOCX $12 \mathrm{~kb}$ )

Additional file 5: Table S3. Primers used for RT-PCR and $\mathrm{QRT}-\mathrm{PCR}$. (DOCX $14 \mathrm{~kb}$ )

\begin{abstract}
Abbreviations
BLAST, basic local alignment search tool; BSA, bulked segregant analysis; CDNA, complementary DNA; CTAB, hexadecyltrimethy ammonium bromide; DUF, domain of unknown function; EMS, ethyl methanesulfonate; FAA, formalin-aceto-alcohol; InDel, insert and deletion; IRGSP, international rice genome sequencing project; LEl, leaf erect index; LRI, leaf rolling index; mRNA, messenger RNA; NCBI, National Center for Biotechnology Information; ORF, open reading frame; REL, rolling and erect leaf; SAM, shoot apical meristem; SNP, single nucleotide polymorphism; SSR, simple sequence repeat
\end{abstract}

\section{Acknowledgements}

We thank the fellows who provided much important advice and help in our lab.

\section{Funding}

This study was supported by the National Natural Science Foundation of China (no.31270299 and 31200148), the Program for New Century Excellent Talents in University of China (NCET-11-0440) and Science and Technology Office of Zhejiang Province (2012C12901-2).

\section{Availability of data and materials}

The dataset supporting the nucleic acid sequence of REL2 is available in the DNA Data Bank of Japan (DDBJ) repository [Accession number: AK243456. http://getentry.ddbj.nig.ac.jp/getentry/na/AK243456/

?format=flatfile\&filetype $=h$ tml\&trace=true\&show_suppressed $=$ false\&limit $=10$ $\mathrm{ry} / \mathrm{ddbj} /$ AK243456?filetype $=\mathrm{html}$ ].

The dataset supporting the protein sequence of REL2 is available in the Universal Protein Resource (UniProt) repository [Accession number: D9ZIP8. http://www.uniprot.org/unipro t/D9ZIP8].

\section{Authors' contributions}

CHS and WQL provided the mutant materials. KMC, WQL and SQY designed the study. SQY carried out all the experiments. HM and YLC participated in the construct of mapping population. PFG participated in the subcellular experiment. LQ involved in the GRT-PCR experiment. SQY wrote the manuscript. KMC and WQL modified the manuscript. KMC gave the final approval of the version to be published. All authors read and approve the final manuscript.

\section{Competing interests}

The authors declare that they have no competing interests.

Consent for publication

Not applicable.

Ethics approval and consent to participate

Not applicable.

Received: 31 January 2016 Accepted: 7 July 2016

Published online: 29 July 2016

\section{References}

Arnon DI (1949) Copper enzymes in isolated chloroplasts. Polyphenoloxidase in Beta vulgaris. Plant Physiol 24:1-15

Bai L, Duan ZQ, Wang JM, An LZ, Zhao ZG, Chen KM (2008) Anatomical and chemical characteristics of a rolling leaf mutant of rice and its ecophysiological properties. Rice Sci 15:201-208

Bateman A, Coggill P, Finn RD (2010) DUFs: families in search of function. Acta Cryst F 66:1148-1152

Bishop GJ, Yokota T (2001) Plants steroid hormones, brassinosteroids: current highlights of molecular aspects on their synthesis/metabolism, transport, perception and response. Plant Cell Physiol 42:114-120

Bowman JL, Eshed Y, Baum SF (2002) Establishment of polarity in angiosperm lateral organs. Trends Genet 18:134-141

Chen QL, Xie QJ, Gao J, Wang WY, Sun B, Liu BH, Zhu HT, Peng HF, Zhao HB, Liu CH, Wang J, Zhang JL, Zhang GQ, Zhang ZM (2015) Characterization of Rolled and Erect Leaf 1 in regulating leave morphology in rice. J Exp Bot 66:6047-6058

Cho S, Yoo S, Zhang H, Lim J, Paek N (2014) Rice NARROW LEAF1 regulates leaf and adventitious root development. Plant Mol Biol Rep 32:270-281

Fang LK, Zhao FM, Cong YF, Sang XC, Du Q, Wang DZ, Li YF, Ling YH, Yang ZL, He GH (2012) Rolling-leaf14 is a 2OG-Fe (II) oxygenase family protein that modulates rice leaf rolling by affecting secondary cell wall formation in leaves. Plant Biotechnol J 10:524-532

Fujino K, Matsuda Y, Ozawa K, Nishimura T, Koshiba T, Fraaije MW, Sekiguchi H (2008) NARROW LEAF 7 controls leaf shape mediated by auxin in rice. Mol Genet Genomics 279:499-507

Goodacre NF, Gerloff DL, Uetzc P (2014) Protein Domains of unknown function are essential in bacteria. mBio 5(1):e00744-13. doi:10.1128/mBio.00744-13

Hibara Kl, Obara M, Hayashida E, Abe M, Ishimaru T, Satoh H, Itoh Jl, Nagato Y (2009) The ADAXIALIZED LEAFI gene functions in leaf and embryonic pattern formation in rice. Dev Biol 334:345-354

Hong Z, Ueguchi-Tanaka M, Matsuoka M (2004) Brassinosteroids and rice architecture. J of Pestic Sci 29:184-188

IRGSP (2005) The map-based sequence of the rice genome. Nature 436:793-800 Jeanmougin F, Thompson JD, Gouy M, Higgins DG, Gibson TJ (1998) Multiple sequence alignment with Clustal X. Trends Biochem Sci 23:403-405

Jiang D, Fang JJ, Lou L, Zhao JF, Yuan SJ, Yin L, Sun W, Peng LX, Guo B, Li XY (2015) Characterization of a null allelic mutant of the rice NAL1 gene reveals its role in regulating cell division. PLOS ONE doi:10.1371/journal.pone.0118169

Kepinski S (2006) Integrating hormone signaling and patterning mechanisms in plant development. Curr Opin Plant Biol 9:28-34

Khush GS, Kinoshita T (1991) Rice karyotype, marker genes and linkage groups. In: Khush GS, Torenniessen GH (eds) Rice Biotechnology. CAB International, Wallingford, pp 83-108

Kidner CA, Timmermans MC (2007) Mixing and matching pathways in leaf polarity. Curr Opin Plant Biol 10:13-20

Li D, Wang L, Wang M, Xu YY, Luo W, Liu YJ, Xu ZH, Li J, Chong K (2009) Engineering OSBAK1 gene as a molecular tool to improve rice architecture for high yield. Plant Biotechnol J 7:791-806

Li L, Shi ZY, Li L, Shen GZ, Wang XQ, An LS, Zhang JL (2010) Overexpression of ACL1 (abaxially curled leaf 1) increased bulliform cells and induced abaxial curling of leaf blades in rice. Mol Plant 3:807-817

Li SG, Ma YQ, He P, Li HY, Chen Y, Zhou KD, Zhu LH (1998) Genetics analysis and mapping the flag leaf roll in rice (Oryza sativa L.). J Sichuan Agric Univ 16:391-393

Liu XF, Li M, Liu K, Tang D, Sun MF, Li YF, Shen Y, Du GJ, Cheng ZK (2016) SemiRolled Leaf2 modulates leaf rolling by regulating abaxial side cell differentiation. J Exp Bot doi:10.1093/jxb/erw029 
Luo YZ, Zhao FM, Sang XC, Ling YH, Yang ZL, He GH (2009) Genetic analysis and gene mapping of a novel rolled leaf mutant $r / 12(t)$ in rice. Acta Agronomica Sinica 35:1967-1972

Luo Z, Yang Z, Zhong B, Li Y, Xie R, Zhao F, Ling Y, He G (2007) Genetic analysis and fine mapping of a dynamic rolled leaf gene, $R L 10(t)$, in rice (Oryza sativa L.). Genome 50:811-817

McConnell JR, Barton MK (1998) Leaf polarity and meristem formation in Arabidopsis. Development 125:2935-2942

Michelmore RW, Paran I, Kesseli RV (1991) Identification of markers linked to disease-resistance genes by bulked segregation analysis: a rapid method to detect markers in specific genomic regions by using segregation population. Proc Natl Acad Sci U S A 88:9828-9832

Moon J, Hake S (2011) How a leaf gets its shape. Curr Opin Plant Biol 14:24-30

Mudgal R, Sandhya SK, Chandra N, Srinivasan N (2015) De-DUFing the DUFs: Deciphering distant evolutionary relationships of Domains of Unknown Function using sensitive homology detection methods. Biol Direct 10:38

Murray MG, Thompson WF (1980) Rapid isolation of high molecular weight plant DNA. Nucleic Acids Res 8:4321-4325

O'Toole JC, Cruz RT (1980) Response of leaf water potential, stomatal resistance, and leaf rolling to water stress. Plant Physiol 65:428-432

Price AH, Young EM, Tomos AD (1997) Quantitative trait loci associated with stomatal conductance, leaf rolling and heading date mapped in upland rice (Oryza sativa L.). New Phytol 137:83-91

Qi J, Qian Q, Bu QY, Li SY, Chen Q, Sun JQ, Liang WX, Zhou YH, Chu CC, Li XG, Ren FG, Palme K, Zhao BR, Chen JF, Chen MS, Li CY (2008) Mutation of the rice narrow leaf1 gene, which encodes a novel protein, affects vein patterning and polar auxin transport. Plant Physiol 147:1947-1959

Shao YJ, Chen ZX, Zhang YF, Chen EH, Qi DC, Miao J, Pan XB (2005a) One major QTL mapping and physical map construction for rolled leaf in rice. Acta Genetica Sinica 32:501-506

Shao YJ, Pan CH, Chen ZX, Zuo SM, Zhang YF, Pan XB (2005b) Fine mapping of an incomplete recessive gene for leaf rolling in rice (Oryza sativa L.). Chinese Sci Bull 50:2466-2472

Shen YJ, Jiang H, Jin JP, Zhang ZB, Xi B, He YY, Wang G, Wang C, Qian L, Li X, Yu QB, Liu HJ, Chen DH, Gao JH, Huang H, Shi TL, Yang ZN (2004) Development of genome-wide DNA polymorphism database for map-based cloning of rice genes. Plant Physiol 135:1198-1205

Shi Y, Chen J, Liu W, Huang Q, Shen B, Leung H, Wu J (2009) Genetic analysis and gene mapping of a new rolled-leaf mutant in rice (Oryza sativa L.). Sci China Ser C 52:885-890

Shi ZY, Wang J, Wan XS, Shen GZ, Wang XQ, Zhang JL (2007) Over-expression of rice OSAGO7 gene induces upward curling of the leaf blade that enhanced erect-leaf habit. Planta 226:99-108

Sussex IM (1955) Morphogenesis in Solanum tuberosum L. experimental investigation of leaf dorsiventrality and orientation in the juvenile shoot. Phytomorphology 5:286-300

Tamura K, Peterson D, Peterson N, Stecher G, Nei M, Kumar S (2011) MEGA5: molecular evolutionary genetics analysis using maximum likelihood, evolutionary distance, and maximum parsimony methods. Mol Biol Evol 28:2731-2739

Tax FE, Durbak A (2006) Meristems in the movies: live imaging as a tool for decoding intercellular signaling in shoot apical meristems. Plant Cell 18: $1331-1337$

Waites R, Hudson A (1995) Phantastica: a gene required for dorsoventrality of leaves in Antirrhinum majus. Development 121:2143-2154

Wang L, Shen RX, Chen LT, Liu YG (2014) Characterization of a novel DUF1618 gene family in rice. J Integr Plant Biol 56:151-158

Wu C, Fu YP, Hu GC, Si HM, Cheng SH, Liu WZ (2010) Isolation and characterization of a rice mutant with narrow and rolled leaves. Planta 232:313-324

Xiang JJ, Zhang GH, Qian Q, Xue HW (2012) SEMI-ROLLED LEAFlencodes a putative glycosylphosphatidylinositol-anchored protein and modulates rice leaf rolling by regulating the formation of bulliform cells. Plant Physiol 159:1488-1500

Xu Y, Wang YH, Long QZ, Huang JX, Wang YL, Zhou KN, Zheng M, Sun J, Chen H, Chen SH, Jiang L, Wang CM, Wan JM (2014) Overexpression of OsZHD1, a zinc finger homeodomain class homeobox transcription factor, induces abaxially curled and drooping leaf in rice. Planta 239:803-816

Yang CH, Li DY, Liu X, Ji CJ, Hao LL, Zhao XF, Li XB, Chen CY, Cheng ZK, Zhu LH (2014) OsMYB103L, an R2R3-MYB transcription factor, influences leaf rolling and mechanical strength in rice (Oryza sativa L.). BMC Plant Biol 14:158
Yan S, Yan CJ, Zeng XH, Yang YC, Fang YW, Tian CY, Sun YW, Cheng ZK, Gu MH (2008) ROLLED LEAF 9, encoding a GARP protein, regulates the leaf abaxial cell fate in rice. Plant Mol Biol 68:239-250

Yuan LP (1997) Super-high yield hybrid rice breeding. Hybrid rice 12:1-6

Zhang GH, Xu Q, Zhu XD, Qian Q, Xue HW (2009) SHALLOT-LIKE1 is a KANADI transcription factor that modulates rice leaf rolling by regulating leaf abaxial cell development. Plant Cell 21:719-735

Zhao SQ, Hu J, Guo LB, Qian Q, Xue HW (2010) Rice leaf inclination2, a VIN3-like protein, regulates leaf angle through modulating cell division of the collar. Cell Res 20:935-947

Zou LP, Sun XH, Zhang ZG, Liu P, Wu JX, Tian CJ, Qiu JL, Lu TG (2011) Leaf rolling controlled by the homeodomain leucine zipper class IV gene Roc5 in rice. Plant Physiol 156:1589-1602

\section{Submit your manuscript to a SpringerOpen ${ }^{\circ}$ journal and benefit from:}

- Convenient online submission

- Rigorous peer review

- Immediate publication on acceptance

- Open access: articles freely available online

- High visibility within the field

- Retaining the copyright to your article

Submit your next manuscript at $>$ springeropen.com 